women devoid of recognised risk factors. Diabetes, obesity, and hypertension are associated with infarction, ${ }^{\overline{5}}$ and their presence may complicate management of the acute phase. During recovery other risk factors may be identified. Though women with hypercholesterolaemia develop heart disease, their risk seems lower than that in men. ${ }^{6}$ In contrast to young men with coronary artery disease, type IV hyperlipidaemia is uncommon in young women with myocardial infarction. Indeed, the relative infrequency of hypertriglyceridaemia in premenopausal women has been suggested as an explanation for some of the sex difference in death rates from ischaemic heart disease. ${ }^{7}$ Three to six months after recovery from myocardial infarction cholesterol and triglyceride values should be checked in fasting blood, and, if abnormal, the doctor should give the appropriate treatment.

Smoking is an important risk factor, the risk rising with the number of cigarettes smoked. At a recent international symposium on coronary heart disease in young women held in Edinburgh, $\mathrm{N}$ Wald showed that smoking interacted with other factors in a multiplicative way, so that with two or more risk factors the risk increased over 100 times. Thus, though we have no information on subsequent outcome, it seems reasonable to advise young women with ischaemic heart disease to stop smoking.

The evidence linking myocardial infarction with oral contraceptives is also convincing. The hospital admission rate for non-fatal myocardial infarction has been calculated as 1.9 per 100000 for married women aged 30 to 39 not using the pill, in contrast with 5.4 per 100000 for those taking an oral contraceptive. In a series of 22 women aged between 31 and 45 years admitted to one coronary care unit with definite myocardial infarction it was estimated that oral contraceptives enhanced the chance of developing myocardial infarction in women whose risk was increased for other reasons. ${ }^{8} \mathrm{~A}$ collaborative survey from 47 hospitals reporting 136 cases of myocardial infarction in women aged 30 to 44 years reached the same conclusion. ${ }^{9}$

Nevertheless, some recent angiographic studies have suggested that some young women taking oral contraceptives may have myocardial infarction without extensive coronary artery disease. ${ }^{1111}$ In two fatal cases necropsy showed minimal arteriosclerotic changes, ${ }^{12}$ and similar pathological evidence was presented by D M Spain of New York at the recent Edinburgh symposium. Some prospect of identifying the women at high risk was suggested by J L Beaumont of Paris, who had shown anti-ethinyloestradiol antibodies in women who had developed thrombotic episodes. These antibodies could be found in about $10 \%$ of pill users, raising the possibility that they might serve as a marker for women at risk.

Once infarction has taken place oral contraceptives must be withdrawn and an alternative means of contraception advised. Anxiety about resuming a normal sex life must be dispelled. The suggestion of sexual frigidity among women developing acute myocardial infarction warrants further investigation. ${ }^{13}$ Coronary angiography should be considered in young women taking oral contraceptives who have developed infarction without other risk factors, for the prognosis in women with small vessel disease may be quite different from that in those with single vessel disease.

${ }^{1}$ Peterson, D R, Thompson, D J, and Chinn, N, fournal of the American Medical Association, 1972, 219, 1423.

${ }^{2}$ Registrar General's Statistical Review of England and Wales. London, HMSO, 1975.

${ }^{3}$ Morris, D C, Hurst, J W, and Logue, R B, American fournal of Cardiology, 1976, 38, 299.

4 Claudon, D G, Claudon, D B, and Edwards, J E, Circulation, 1972, 45, 259.
5 Mann, J I, et al, British Medical fournal, 1975, 2, 241.

6 Slack, J, and Evans, K A, fournal of Medical Genetics, 1966, 3, 239.

Mann, J I, and Thorogood, M, British Heart fournal, 1975, 37, 790.

Radford, D J, and Oliver, M F, British Medical fournal, 1973, 3, 428

${ }^{9}$ Arthes, F G, and Masi, A T, Chest, 1976, 70, 574.

1" Waxler, E B, et al, American fournal of Cardiology, 1971, 28, 96.

${ }^{11}$ Engel, H-J, Hundeshagen, H, and Lichtlen, P, British Heart fournal, 1977, 39, 477.

12 Weiss, S, New England Journal of Medicine, 1972, 286, 436

13 Abramov, L A, Psychosomatic Medicine, 1976, 38, 418.

\section{How important are genetic influences on alcohol dependence?}

Both the amount of alcohol drunk and the risk of dependence vary from country to country, among occupational groups, and, above all, between the sexes. These rates change from one generation to the next, for people drink-or drink to excessfor many different reasons, and alcohol dependence creates family problems. At first sight, therefore, it might seem a forlorn task ${ }^{1}$ to look for genetic factors predisposing to the disorder.

Yet much of the same sort of evidence that suggests there are genetic factors in intelligence and schizophrenia applies to alcoholism. ${ }^{2}$ The very fact that an individual must start to drink before he can suffer withdrawal symptoms permits approaches to genetic investigation that are not possible or are less appropriate in other forms of human behaviour. Animal studies $^{3}$ have shown repeatedly that strains of rats and mice differ in their preference for or avoidance of alcohol, and strains can be bred selectively for such behaviour and the susceptibility to withdrawal symptoms. Some strain differences have been associated with the ability to metabolise acetaldehyde. Rodents, like men, can work to get alcohol, drink to intoxication, and become dependent on it-though estimates of heritability or biochemical mechanisms calculated from animal experiments should not be expected to apply to any particular human population.

Compared with Caucasians, Oriental people more often become flushed after small doses of alcohol, ${ }^{4}$ and they show differences in the frequency of the genetic variants of alcohol dehydrogenase. Genetic differences may also influence the rate of elimination of alcohol from the blood. A pharmacogenetic approach to the problem of alcohol dependence may therefore offer some promise. While the association between a disturbance of colour vision and chronic alcoholism is no longer thought to have a genetic basis, ${ }^{5}$ the non-secretion of the ABH blood group substances ${ }^{6}$ may possibly turn out to be an example of a known gene with a minor effect on predisposition to alcoholism. Immune response studies have suggested that genetic factors may also be implicated in some complications of alcohol addiction, such as cirrhosis. ${ }^{\text {? }}$

At present, however, what evidence we have on genetic and environmental influences still depends largely on comparisons of the frequency of alcoholism in relatives and contacts of alcoholics. Some of the evidence is contradictory, and almost all $^{8}$ of it deals with men. There is a genuine increase in the risk for the sons and brothers of alcoholics (rates of around $20 \%$ being fairly typical) compared with men unrelated to an alcoholic, ${ }^{910}$ but on its own such a finding is of no conclusive help in differentiating genetic and environmental transmission. An almost equally high rate in grandsons ${ }^{11}$ and half-brothers ${ }^{12}$ 
suggests the influence of the social environment. Twin studies show a genetic influence on alcohol consumption, ${ }^{13} 14$ but even in identical twins reared together concordance for alcohol dependence is far from complete. ${ }^{2}$

If being brought up by an alcoholic parent were itself of major importance, sons of alcoholics adopted into nonalcoholic families would be expected not to have the same raised incidence of the disorder. Nevertheless, recent studies in Denmark ${ }^{15}{ }^{16}$ found such sons to have a higher alcoholism rate than a matched group of adoptees whose biological parents were not recorded as alcoholic-and the rate was no less high than in non-adopted sons of the same alcoholics. Shared family environment seemed to be irrelevant. Furthermore, the genetic influence appeared to be more specific than might have been expected: the adopted sons did not have an increased risk of depression or other psychiatric disorder.

Goodwin and his colleagues ${ }^{17}$ have now extended their study of Danish adoptees to the daughters of (mostly male) alcoholics. Female alcoholism is relatively rare, and in some studies the rate reported among the daughters of alcoholics was only $6-9 \%$. So we should not expect statistically significant results from a study based on 49 women, eight of them still under the age of 30. Alcohol-related problems (but not depression) in these women were indeed raised over what might have been expected in the general population, but the control group of 47 girls adopted from non-alcoholic parents also apparently had a raised incidence of alcoholism-two women who had needed hospital care had had adoptive fathers described as problem drinkers.

It would be a gross oversimplification to say that male alcoholism is genetic and female environmental; but there is a widespread belief that women have a higher threshold for alcohol addiction, which implies that it takes more of the relevant biological or environmental factors to make a woman addicted. Those who are affected have a higher mortality rate and incidence of cirrhosis than men. ${ }^{18}$ Using the few data available, American workers ${ }^{19}$ have argued that male and female alcohol dependence need not be based on different genotypes. The rates they found in male relatives of male probands were too high to be accounted for entirely by shared family genes, shared family environments, and the different thresholds for the two sexes: social, non-familial environmental factors seemed also to be important. Certainly the environmental factors promoting alcohol dependence look to be different in the sexes, with men being more vulnerable to social pressures and women to stresses within the family. Unfortunately the most certain thing that we can now say about female alcoholism ${ }^{20}$ is that it is showing a "new and deplorable rise"-not, presumably, for genetic reasons.

1 Slater, E, and Cowie, V, The Genetics of Mental Disorders. London, Oxford University Press, 1971.

2 Shields, J, in Alcoholism. New Knowledge and New Responses, eds Griffith Edwards and Marcus Grant, p 117. London, Croom Helm, 1977.

3 Eriksson, K, in Psychopharmacogenetics, ed B E Eleftheriou, p 127. New York, Plenum Publishing Corporation, 1975.

4 Wolff, P H, American fournal of Human Genetics, 1973, 25, 193.

5 Reid, N C R W, et al, British Medical fournal, 1968, 2, 463.

${ }^{6}$ Swinson, R P, and Madden, J S, Quarterly fournal of Studies in Alcohol, $1973,34,64$.

${ }^{7}$ Bailey, R J, et al, British Medical fournal, 1976, 2, 727.

${ }^{8}$ Winokur, G, et al, Archives of General Psychiatry, 1970, 23, 104.

9 Åmark, C, Acta Psychiatrica Neurologica Scandinavica, 1951, suppl 70.

10 Bleuler, M, in Etiology of Chronic Alcoholism, ed O Diethelm, p 110 Springfield, Thomas, 1955.

11 Kaij, L, and Dock, J, Archives of General Psychiatry, 1975, 32, 1379.

12 Schuckit, M A, Goodwin, D A, and Winokur, G, American fournal of Psychiatry, 1972, 128, 1132.

${ }^{13} \mathrm{Kaij}, \mathrm{L}$, Alcoholism in Twins. Stockholm, Almqvist and Wiksell, 1960

14 Partanen, J, Bruun, $\mathrm{K}$, and Markkanen, $\mathrm{T}$, Inheritance of Drinking Behavior. Helsinki, Finnish Foundation for Alcohol Studies, 1966.
15 Goodwin, D W, et al, Archives of General Psychiatry, 1973, 28, 238

${ }^{16}$ Goodwin, D W, et al, Archives of General Psychiatry, 1974, 31, 164.

17 Goodwin, D W, et al, Archives of General Psychiatry, 1977, 34, 751.

18 Dahlgren, L, and Myrhed, M, Acta Psychiatrica Scandinavica, 1977, 56, 81.

19 Reich, T, Winokur, G, and Mullaney, J, in Genetic Research in Psychiatry, eds R R Fieve, D Rosenthal and H Brill, p 259. Baltimore and London, Johns Hopkins, 1975.

${ }^{20}$ British Medical fournal, 1977, 2, 914.

\section{Low key in Copenhagen}

EEC doctors produced no dramatic new initiatives at their meeting last week in Copenhagen. The 1977 annual plenary session of the Standing Committee of Doctors of the EEC, while low key, marked three firsts. The Danish Medical Association was running its first full meeting (the Danes took over the secretariat from the BMA in January this year ${ }^{1}$ ); the Standing Committee held its first press conference; and it was the first time that full delegations from the Nine had met since the directive permitting the free movement of doctors had become part of Community law. ${ }^{2}$ Though free movement is now allowed, not all countries have yet passed the necessary legislation, so it is too early to judge the effects of the new freedom. Some preliminary figures for 1977 were given to the plenary session: these have to be interpreted with caution, as they include "foreign" doctors who were merely regularising their existing practices in their host country. For example, Belgium had admitted 50 doctors, Denmark nine (two from the UK), and France 62 (four from the UK), while Holland reported 109 applications in the first six months of 1977, with 53 of those now fully registered (19 from the UK).

When free movement was discussed during the meetingand the practical problems associated with it became apparent on various occasions during the two days-the British came in for particular criticism, led by the Germans, over the language test introduced by our Government. The general consensus was that this test breaks the Common Market rules, so it seems only a matter of time before the British Government is taken to the European Court at Luxembourg to answer for its action. Nevertheless, though the British have come out into the open with a language test, apparently some other countries are erecting informal barriers that have much the same effect. So, clearly, there are some delicate discussions to be held about this sensitive area.

The Standing Committee, chaired with quiet determination by Dr Erik Holst of the DMA, held its first ever formal press conference at lunchtime on the first day. The timing, though convenient for the international press who attended, proved unhappy for the conference. With the reasonable desire to present some outcome to the media, the platform attempted to reach agreement on several new proposals during the first morning. In this sort of international gathering, thorough ground work and ample discussion time are necessary to ensure the smooth passage of fresh initiatives. As these were missing, a three-part recommendation on rising health costs raised more dissension than accord and-despite a valiant compromise effort later in the meeting by Dr Alan Rowe, the British delegation's leader-never saw the light of day. Another major proposal, this time from Britain, calling for a coordinating health directorate (health affairs fall into several different Commission directorates at Brussels) and a companion professional health advisory committee suffered the same fate. 